\title{
On the Incidence of Pulmonary Embolism in Spinal Arthrodesis and the Need for Better Evidence and Prevention Guidelines
}

\author{
Zachary J. Senders, BS, Benjamin Zussman, BS, James S. Harrop, MD \\ Department of Neurological Surgery, Jefferson Medical College, Philadelphia, PA
}

Keywords: Degenerative disk disease, pulmonary embolism, scoliosis, spinal arthrodesis, spinal fusion

\section{Introduction}

Pulmonary Embolism (PE) is a rare but serious event that may occur after spinal surgery. Vascular endothelial damage during surgery and immobilization of the patient after surgery contribute to a higher risk of thrombosis and subsequent PE. ${ }^{6}$ Prophylaxis including intermittent pneumatic compression stockings, heparin, and other interventions is often employed by the treatment team to lower the risk of thromboembolic complications. In orthopedic, trauma, burn and other high-risk surgical patients, the incidence of PE has been thoroughly studied, and this knowledge has been used to establish prophylaxis guidelines specifically for these patients. ${ }^{7}$ The incidence of PE in spinal fusion patients, however, is less well studied, and definitive prophylaxis guidelines are lacking. The aim of this article is to review what is known about the incidence of PE in spinal arthrodesis patients, and describe the need for better medical evidence and prevention guidelines on this issue.

\section{Literature Review}

Smith et al, ${ }^{17}$ in the largest published study, reported on 108,419 patients undergoing lumbar microdiscectomy, anterior cervical discectomy and fusion, and lumbar stenosis decompression procedures. They reported a PE incidence of $0.14 \%$. Only one other study, a meta analysis, acheived a sample size greater than 1,000 (Table 1). This study by Sansone et a ${ }^{15}$ reported a PE incidence of $0.06 \%$ in elective spinal fusion patients. In a study by Schizas et al, ${ }^{16} 270$ spinal fusion patients were given heparin prophylaxis and $2.2 \%$ developed PE.

Although other studies had limited sample sizes, they address more specific sub-groups of spinal arthrodesis patients. Platzer et a ${ }^{14}$ studied 978 patients that were admitted to a level- 1 trauma center and subsequently underwent spinal fusion for traumatic indications and noted a PE incidence of $0.92 \%$. McKinley et $\mathrm{a}^{10}$ further studied 779 spinal cord injury (SCI) patients and reported the highest incidence of PE at $2.0 \%$. In a group of patients determined to be at high risk for PE, Leon et al ${ }^{9}$ placed prophylactic inferior vena cava filters after spinal fusion surgery and reported a subsequent PE incidence of $1.4 \%$ in these patients.

Several studies have identified an association between spinal surgical approach and the incidence of PE. Pateder et $\mathrm{al}^{12}$ followed 407 spinal patients and noted a PE incidence of $0.65 \%$ with posterior approach and $4.5 \%$ with anterior or combined anterior-posterior approach. Kim et al ${ }^{8}$ studied 119 patients and reported an incidence of $1.6 \%$ with posterior approach and $7.5 \%$ with combined anterior-posterior approach. Dearborn et $\mathrm{al}^{3}$ studied 116 patients and reported an incidence of $0.5 \%$ with posterior approach and $6.0 \%$ with combined anterior-posterior approach. Epstein et $\mathrm{al}^{4}$ reported an incidence of $1.5 \%$ with anterior approach, Cho et $\mathrm{al}^{1}$ reported an incidence of $2.1 \%$ with posterior approach, and Piasecki et a $\mathrm{l}^{13}$ reported an incidence of $7.6 \%$ with combined anterior-posterior approach, although these studies did not directly compare different approaches.

Other studies examined the incidence of $\mathrm{PE}$ after spinal fusion in specific surgical regions. Oskouian et $\mathrm{al}^{11}$ studied 207 patients and reported a PE incidence of $0.48 \%$ in thoracolumbar fusions, while Wood et a ${ }^{19}$ studied 136 patients and reported an incidence of $0.70 \%$ with thoracolumbar fusions. Neither study directly compared the PE incidence in different spinal regions.

\section{Discussion}

The incidence of PE in spinal fusion patients is reported in the range of $0.06 \%-7.6 \%$. This confirms that $\mathrm{PE}$ is a rare event in these patients, but occurs often enough to warrant attention from the medical team. The range of reported incidences, however, is wide. The only large-scale study ${ }^{17}$ reported an incidence of $0.14 \%$, but studied a specific group of low risk patients. Other studies that report much higher incidences are underpowered and focus only on high-risk patients. These discrepancies in the literature highlight the need for largerscale studies inclusive of patients of all risk stratifications in order to accurately determine the overall incidence of PE after spinal fusion.

Studies that focus on spinal fusion indicated for trauma generally report a higher incidence of PE than studies focused on elective or nontrauma spinal fusions. ${ }^{10,14,15,17}$ No study directly compares trauma versus non-trauma groups, however. A study directly comparing the incidence of PE in non-trauma and trauma spinal fusion patients would be useful to confirm that trauma patients do in fact have higher risks for $\mathrm{PE}$, and might encourage additional prophylaxis and stricter observation in this population.

Likewise, studies that focus on PE incidence depending on the approach to spinal fusion surgery report a higher incidence in combined anterior/posterior approach than in anterior or posterior approaches alone. ${ }^{3,8,12}$ This link, however, is not well established in the literature because few studies compare approaches accurately and those that do are underpowered. To establish a link between surgical approach and a higher incidence of PE, larger studies are necessary. Furthermore, PE incidence also may vary depending on the region of spinal fusion, but too few studies have been published to suggest a relationship.

Over the past decades, several guidelines concerning the management of venous thromboembolism and PE prophylaxis have been produced, such that at present, many spinal fusion patients receive postoperative anticoagulation, compression devices, and elastic stockings. ${ }^{2,5,718}$ However it is unclear in the literature how these advancements in prophylactic guidelines and treatments have affected the incidence of $\mathrm{PE}$ in spinal fusion patients over time. At present there is little published longitudinal data assessing these effects. A recent analysis at our institution using the Nationwide Inpatient Sample showed that despite these medical advancements, the incidence of $\mathrm{PE}$ in spinal fusion patients has steadily remained about $0.2 \%$ since $1988 .{ }^{20}$ 
Table 1. Studies of Pulmonary Embolism Incidence in Spinal Arthrodesis Patients

\begin{tabular}{|c|c|c|c|}
\hline Author & Number of Patients & Procedure/indication & Incidence \% \\
\hline JS Smith, et al. & 108,419 & $\begin{array}{l}\text { Lumbar microdiscectomy, anterior cervical discectomy and fusion, lumbar } \\
\text { stenosis decompression }\end{array}$ & $0.14 \%$ \\
\hline JM Sansone, et al. & 4,383 & Elective spinal fusion & $0.06 \%$ \\
\hline P Platzer, et al. & 978 & Spinal fusion after trauma & $0.92 \%$ \\
\hline W McKinley, et al. & 779 & Spinal fusion after spinal cord injury & $2.00 \%$ \\
\hline \multirow[t]{3}{*}{ DB Pateder, et al. } & \multirow[t]{3}{*}{407} & Reconstructive spinal fusion & $2.40 \%$ \\
\hline & & Posterior approach & $0.65 \%$ \\
\hline & & Anterior and Anterior/Posterior approach & $4.50 \%$ \\
\hline MD Smith, et al. & 317 & Reconstructive spinal fusion & $0.32 \%$ \\
\hline \multirow{2}{*}{ C Schizas, et al. } & \multirow[t]{2}{*}{270} & All fusions & $2.20 \%$ \\
\hline & & Anterior and Anterior/Posterior lumbar or thoracolumbar fusion & $4.20 \%$ \\
\hline RJ Oskouian Jr., et al. & 207 & Anterior thoracolumbar spinal fusion & $0.48 \%$ \\
\hline NE Epstein, et al. & 200 & Anterior approach & $1.50 \%$ \\
\hline KB Wood, et al. & 136 & Thoracolumbar reconstruction & $0.70 \%$ \\
\hline \multirow[t]{2}{*}{ HJ Kim, et al. } & \multirow[t]{2}{*}{119} & Posterior Approach & $1.60 \%$ \\
\hline & & Anterior/Posterior approach & $7.50 \%$ \\
\hline \multirow[t]{3}{*}{ JT Dearborn, et al. } & \multirow[t]{3}{*}{116} & All fusions & $2.20 \%$ \\
\hline & & Posterior approach & $0.50 \%$ \\
\hline & & Anterior/Posterior approach & $6.00 \%$ \\
\hline L Leon, et al. & 74 & "High-risk" spinal fusion & $1.40 \%$ \\
\hline DP Piasecki, et al. & 66 & Anterior/Posterior approach & $7.60 \%$ \\
\hline KJ Cho, et al. & 47 & Posterior approach & $2.10 \%$ \\
\hline
\end{tabular}

Further analysis is necessary to determine if the current prophylaxis guidelines and treatments are adequate.

\section{Conclusion}

Pulmonary embolism (PE) is a rare and dreaded event that may occur after spinal fusions, the incidence of which is reported in the literature between $0.06 \%-7.6 \%$. Though some studies report a higher incidence of PE in trauma patients and those undergoing a combined anterior/posterior procedure, more complete and higher powered investigations are necessary to confirm these findings. Longitudinal studies are lacking, and will be necessary to determine if $\mathrm{PE}$ prophylaxis in spinal fusion patients has been effective in the long term.

\section{References}

1. Puusepp M. Variete rare de teratome sousdural de la region 1. Cho KJ, Suk SI, Park SR, Kim JH, Kim SS, Choi WK, et al: Complications in posterior fusion and instrumentation fo degenerative lumbar scoliosis. Spine (Phila Pa 1976) 32:22322237,2007
2. Collen JF, Jackson JL, Shorr AF, Moores LK: Prevention of venous thromboembolism in neurosurgery: a metaanalysis. Chest 134:237-249, 2008

3. Dearborn JT, Hu SS, Tribus CB, Bradford DS: Thromboembolic complications after major thoracolumbar spine surgery. Spine (Phila Pa 1976) 24:1471-1476, 1999

4. Epstein NE: Intermittent pneumatic compression stocking prophylaxis against deep venous thrombosis in anterior cervical spinal surgery: a prospective efficacy study in 200 patients and literature review. Spine (Phila Pa 1976) 30:25382543,2005

5. Fang MC, Maselli J, Lurie JD, Lindenauer PK, Pekow PS, Auerbach AD: Use and outcomes of venous thromboembolism prophylaxis after spinal fusion surgery. J Thromb Haemost 9:1318-1325, 2011

6. Fields JM, Goyal M: Venothromboembolism. Emerg Med Clin North Am 26:649-683, viii, 2008

7. Geerts WH, Bergqvist D, Pineo GF, Heit JA, Samama CM, Lassen MR, et al: Prevention of venous thromboembolism American College of Chest Physicians Evidence-Based Clinical Practice Guidelines (8th Edition). Chest 133:381S453S, 2008

8. Kim HJ, Kepler C, Cunningham M, Rawlins B, Boachie-Adjei $\mathrm{O}$ : Pulmonary embolism in spine surgery: a comparison of combined anterior/posterior approach versus posterior approach surgery. Spine (Phila Pa 1976) 36:177-179, 2011
9. Leon L, Rodriguez H, Tawk RG, Ondra SL, Labropoulos N, Morasch MD: The prophylactic use of inferior vena cava filters in patients undergoing high-risk spinal surgery. Ann Vasc Surg 19:442-447, 2005

10. McKinley W, Meade MA, Kirshblum S, Barnard B: Outcome of early surgical management versus late or no surgical intervention after acute spinal cord injury. Arch Phys Med Rehabil 85:1818-1825, 2004

11. Oskouian RJ, Jr., Johnson JP: Vascular complications in anterior thoracolumbar spinal reconstruction. J Neurosurg 96:1-5, 2002

12. Pateder DB, Gonzales RA, Kebaish KM, Antezana DF, Cohen DB, Chang JY, et al: Pulmonary embolism after adult spinal deformity surgery. Spine (Phila Pa 1976) 33:301-305, 2008

13. Piasecki DP, Poynton AR, Mintz DN, Roh JS, Peterson MG, Rawlins BA, et al: Thromboembolic disease after combined anterior/posterior reconstruction for adult spinal deformity: a prospective cohort study using magnetic resonance venography. Spine (Phila Pa 1976) 33:668-672, 2008

14. Platzer P, Thalhammer G, Jaindl M, Obradovic A, Benesch T, Vecsei $\mathrm{V}$, et al: Thromboembolic complications after spinal surgery in trauma patients. Acta Orthop 77:755-760, 2006

15. Sansone JM, del Rio AM, Anderson PA: The prevalence of and specific risk factors for venous thromboembolic disease following elective spine surgery. J Bone Joint Surg Am 92:304 313,2010 
16. Schizas C, Neumayer F, Kosmopoulos V: Incidence and management of pulmonary embolism following spinal surgery occurring while under chemical thromboprophylaxis. Eur Spine J 17:970-974, 2008

17. Smith JS, Fu KM, Polly DW, Jr., Sansur CA, Berven SH Broadstone PA, et al: Complication rates of three common spine procedures and rates of thromboembolism following spine surgery based on 108,419 procedures: a report from the Scoliosis Research Society Morbidity and Mortality Committee. Spine (Phila Pa 1976) 35:2140-2149, 2010
18. Stein PD, Matta F, Dalen JE: Is the Campaign to Prevent VTE in Hospitalized Patients Working? Chest 139:1317-1321, 201

19. Wood KB, Kos PB, Abnet JK, Ista C: Prevention of deep-vein thrombosis after major spinal surgery: a comparison study of external devices. J Spinal Disord 10:209-214, 1997
20. Zussman B, Senders Z, Maltenfort M, Sharan A, Ratliff, Harrop J: The incidence of pulmonary embolism in patients treated with spinal fusion procedures for different surgical indications, in Congress of Neurological Surgeons Annual Meeting. Washington, D.C., 2011

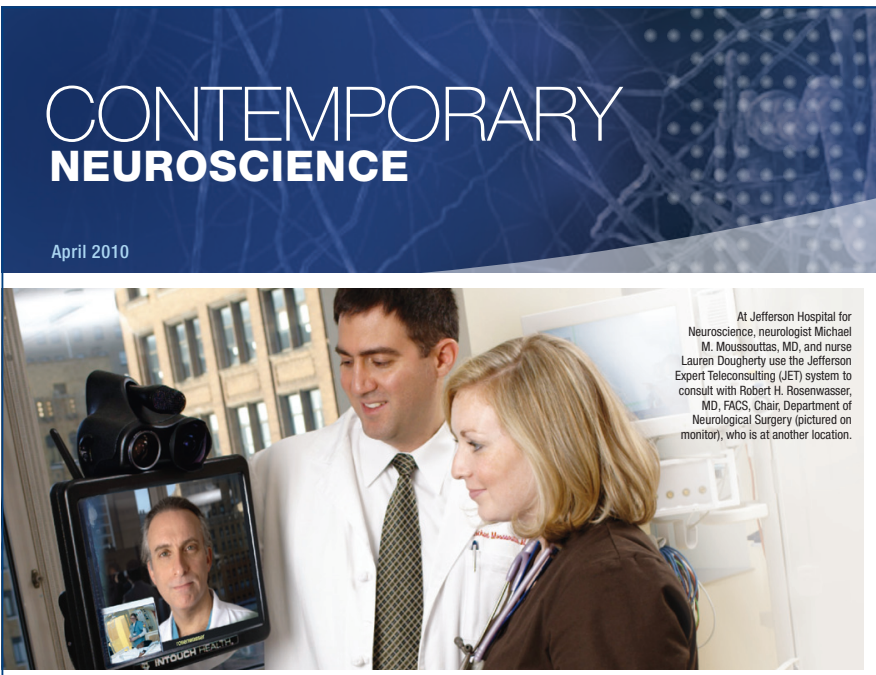

Announcing Jefferson's Teleconsulting (JET) Robotic System for Help with Diagnosis and Treatment of Time-Sensitive Neurovascular Diseases

"Time is brain" is the credo among healthcare professionals for diagnosing and treating tim sensitive neurovascular diseases, including arteriovenous malformations (AVMs), brain aneurysms and, especially, stroke. The blood-clot busting medication tissue plasminogen activator (tPA), for example, must be administered to a patient having a stroke within 4.5 hours for best chance of functional recovery. Timely performance of neurosurgical procedures to remove AVMs and aneurysms are similarly urgent. Yet many community hospitals have limited experienced staff and technology to diagnose and treat patients quickly and accurately.

Now, to provide sophisticated care and expertise to patients at hospital emergency rooms in small community hospitals in distant areas of eastern Pennsylvania, south and central New Jersey, and Delaware, Jefferson Hospital for Neuroscience (JHN) in Philadelphia is launching Jefferson Expert Teleconsulting (JET) the region's first univerity high-tech mobile robotic system for neuroscience

"JET places all of our resources - among them, dualtrained neurosurgeons, advanced technology, and leading-edge clinical trials in which we partner with the National Institutes of Health - at the disposal of patients, their families and physicians in need of a second, expert opinion" says Robert H. Rosenwasser MD, FACS, opinion, says Robert Hestonss, MD, FACS, Surgery, JHN and Jefferson Medical College of Thoma Jefferson University. "Its greatest value is for timely diagnosis and application of treatment for time-sensitive neurovascular diseases, especially stroke."

Enhancing level of care

"We want to partner with hospitals in othe

communities to help advance stroke care throughou

the region. As the leading provider of stroke care in the region, we have an obligation to do that," adds Pamela Kolb, Vice President, Neuroscience Service, JHN.

Supported by Thomas Jefferson University, leading academic center, JHN is the region's only dedicated hospital for neuroscience and leading most experienced and comprehensive center fo diagnosis and treatment of stroke and cerebrovascula disease. JHN's Acute Stroke Center is the largest such facility, with more board-certified neurocritical care physicians than most in the greater Delaware Valley. It is a so Joint Cominging stroke center.

"Stroke is the third-leading cause of death in the United States but the leading cause of disability, by a factor of five over any other disease," Dr. Rosenwasse notes. "Given its prevalence and time-sensitive nature, it is alarming how few people receive treatment in the appropriate amount of time. With JET, even hospitals in remote areas can provide patients with expert consultation and disposition of appropriate care from an experienced neurologist or neurological surgeon merianced neurologist or neurological surgeon critical difference. It's a very cost-effective approach to providing 24/7 onsite coverage and expertise."

How JET works

Each participating hospital is supplied with a mobile robotic platform, manufactured by InTouch Health ${ }^{\circ}$ of Santa Barbara, CA, that enables the JHN Network physician to be remotely present. JET's panoramic visualization system and easy-to-use control interface afford physicians, patients and hospital staff a safe and affective intions
Pioneering Leading-Edge Treatments Jefferson Hospital for Neuroscience staff have helped to develop atmor have $\mathrm{N}$.odog to he region leadingfor open brain surgery for stroke, brain aneurysms and AVMs. Among them:

- Intra-arterial thrombolysis with tPA - pharmacologica blood clot-dissolving

- Mechanical thrombectomy devices - e.g., Merci Retrieval System ${ }^{\circ}$

- Wingspan stent - FDA-approved mesh tube to open blocked arteries in the brain after clot-dissolving drug

- Coiling, gluing and stenting of brain aneurysms reduces need for open brain surgery

InTouch's remote presence devices are the first and only with FDA approval. The robots allow direct connection to medical devices such as electronic connection to medical devices such as electronic
stethoscopes, otoscopes and ultrasound to transmit medical data to the remote physician.

"Should a patient arrive in the ER of a hospital that' located, say, three hours away from Jefferson and either doesn't have a neurologist or neurosurgeon available or has a neurologist who needs to consult with a neurosurgeon," Dr. Rosenwasser, explains, "the attending physician contacts JHN. The JHN Network specialist on call then uses a laptop to connect to the remote hospital via the robot, obtain a medical history by speaking directly with the patient and/or family members, examine the patient and determine what therapy is immediately needed, in real time, without delay. Finally, a decision is made either to admit the patient to the local hospital's Critical Care Unit or transfer him or her to the Jefferson Acute Stroke Center by JeffSTAT Jefferson's transport service, or the hospital's own service."

"Patients may not need to be transferred - they can stay in their own community and be treated very successfully there, thanks to this program," says Ms. Kolb. "And most patients want to stay close to home. JET enables them to receive sophisticated medical care without having to travel long distances."

"It also serves as an educational program," adds Dr. Rosenwasser. "As a teaching center, JHN will use JET to share our clinical protocols with participating hospitals so that they can enhance stroke care withi their communities. On the other hand, should the patient need an advanced neurosurgical procedure [See sidebar], we can arrange for prompt transfer" JHN continues to set the standard worldwid
for state-of-the-art care for time-sensitive neurovascular diseaser. about these and other treatments, visit

\section{Jefferson.}

Hospital for Neuroscience 